\title{
Expanding the Concept of Usability
}

\author{
Alex Koohang \\ University of Wisconsin - Milwaukee, Milwaukee, WI, USA \\ koohang@uwm.edu
}

\begin{abstract}
Building on a stream of previous literature regarding the usability properties that are fundamental to the e-learning courseware, this study attempted to assess users' current views about applied elearning usability and users' perceived importance of e-learning usability design features with consideration to the variable of experience - namely, users' prior experience with the Internet and amount of time users spend weekly on the e-learning courseware. The importance of experience in the e-learning instructional design process regarding usability is discussed. The assertion is made that usability is a multi-dimensional concept with experience being the new dimension. Discussion and recommendation are made for a clear means to guide e-learning usability improvements in the e-learning instructional design process giving careful attention to the variable of experience as a new dimension.
\end{abstract}

Keywords: Usability Properties, Usability Attributes, Experience, E-Learning Usability, Users' Views

\section{Introduction}

E-learning, a new paradigm of distance education, is reshaping teaching and learning. Perhaps the most comprehensive definition of e-learning has been offered by Learnframe (2001) in which it states that e-learning is "using electronic applications and processes to learn. E-learning applications and processes include Web-based learning, computer-based learning, virtual classrooms, and digital collaboration. Content is delivered via the Internet, intranet/extranet, audio or video tape, satellite TV, and CD-ROM.”

Adkins (2002) predicts that U.S. e-learning industry revenues will total $\$ 83.1$ billion by 2006 . This amount is divided among the following categories: K-12 academic $\$ 11.0$ billion; higher education $\$ 23.0$ billion; recruiting and staffing $\$ 4.6$ billion; corporations and business $\$ 16.4$ billion; government $\$ 2.7$ billion; e-learning simulation $\$ 6.1$ billion; vocational $\$ 8.6$ billion, consumer $\$ 7.3$ billion; and associations $\$ 3.4$ billion.

Based on Adkins' (2002) report, it is evident that e-learning is becoming increasingly popular. Perhaps less evident is e-learning's ability to deliver a quality educational experience. Given this sentiment, e-learning instructional

Material published as part of this journal, either online or in print, is copyrighted by the publisher of Informing Science. Permission to make digital or paper copy of part or all of these works for personal or classroom use is granted without fee provided that the copies are not made or distributed for profit or commercial advantage AND that copies 1) bear this notice in full and 2) give the full citation on the first page. It is permissible to abstract these works so long as credit is given. To copy in all other cases or to republish or to post on a server or to redistribute to lists requires specific permission and payment of a fee. Contact Editor@inform.nu to request redistribution permission. design aspirations must be to enhance and optimize learning. Instructional design in general is planning and constructing successful and valuable instructional materials. Instructional design relies on learning models and theories to optimize learning. Broderick (2001) states that "Instructional Design is the art and science of creating an instructional environment and 
materials that will bring the learner from the state of not being able to accomplish certain tasks to the state of being able to accomplish those tasks.” Instructional design has been developed that draws on learning theories and models including behaviorist, cognitive, humanist, constructivist, mastery learning and taxonomy, psychological stages in life cycle, multiple intelligence, and andragogy (pedagogy for adults).

There is consensus among scholars that instructional design for e-learning necessitates the use of appropriate learning models geared explicitly to the needs and specifications of learners (Egbert \& Thomas, 2001; Pimentel, 1999; Randall, 2001). The importance of including appropriate learning models in designing e-learning curriculum has been widely acknowledged in previous research (Gold, 2001; Huang, 2000, 2002, Koohang \& Durante, 2003; Pimentel, 1999; Sherry \& Morse, 1995).

In addition, there are certain key elements that influence learning within the e-learning environment. These are learner consideration, learning task, learning content, content organization, instructional strategies, media, learning environment, quality assessment of instruction, selection of materials for delivery, and evaluation/feedback (Moore \& Kearsley, 1996; Sherry \& Morse, 1995; Simonson, Smaldino, Albright, \& Zvacek, 2000).

The e-learning instructional design process, however, has primarily focused on insertion and or adaptation of learning principles/theories, and learning models into the e-learning curriculum. Little research has been done regarding the usability of e-learning courseware and its significance in the e-learning instructional design process. Koohang and du Plessis (2004) constructed a three element e-learning instructional design process model that includes not only the elements of instructional design as expressed by content and learning as expressed by user characteristics, but it also includes usability properties as expressed by system features. The authors believe that inclusion of usability properties within the e-learning instructional design process is vital to successful e-learning curriculum. In addition, recent studies by Mehlenbacher (2000), Koohang \& Weiss (2003), and Koohang (2004) have revealed the importance of including usability into the elearning instructional design process. Furthermore, Crowther \& Keller (2004) assert that including usability as a part of evaluation improves the quality and effectiveness of Web-based instruction.

\section{Usability, Usability Attributes, and Usability Properties}

In general, usability is the extent to which a product or a system enables users to achieve specified goals. Usability is the ability of a product or system to effectively and efficiently fulfill the needs and specifications of users. Usability is essential to user satisfaction and user acceptance of a product or system. It is the measure of the quality of the user's experience when interacting with a product or system (Dumas \& Redish, 1993; Guillemette, 1989; Nielsen 1993, 2000; Rosenbaum, 1989; Rubin, 1994; Shackel 1991).

Usability attributes are the outcome of a usable product or system. In other words, if a system is usable, one should experience both objective and subjective usability attributes. The objective usability attributes are effectiveness, learnability, flexibility, understandability, memorability, and reliability. The subjective usability attributes include positive attitude, user satisfaction, and product/system attractiveness (International Organization for Standardization [ISO], 1998; International Organization for Standardization /International Electrotechnical Commission [ISO/IEC], 1991; Nielsen, 1993; Shackle, 1991).

To achieve usability attributes, usability properties must be designed into the product or system. Usability properties are inherent to user interface design and make a product or system usable (Dumas \& Redish, 1993; Guillemette, 1989; Holms, 2002, ISO; 1998; ISO/IEC, 1991; Nielsen 1993, 2000; Rosenbaum, 1989; Rubin, 1994; Shackel 1991). 
Koohang (2004) stated that usability of e-learning courseware is a critical aspect of the e-learning instructional design process. The author examined users' current perceptions toward e-learning courseware usability with 17 items that characterized e-learning courseware usability. The subjects of his study were 201 students enrolled in an accelerated undergraduate hybrid program. It was found that users' prior experience with the Internet and the amount of time they spent on the e-learning courseware were significant factors. In other words, subjects with more prior experience with the Internet had significantly higher positive perceptions toward the e-learning courseware usability. Similarly, subjects who spent more time on the e-learning courseware showed significantly higher positive perceptions toward the e-learning courseware usability.

The present study builds on a stream of usability research conducted by Koohang (2004) and attempts to further achieve the following:

- Refine and expand the properties that characterize e-learning courseware usability from 17 to 19 items. The additional 2 items are feedback and direction. These items were selected because e-learning courseware are inherently interactive and are used in an iterative fashion. The usability properties were taken from previous literature (Dumas \& Redish, 1993; Guillemette, 1989; Holms, 2002; ISO, 1998; ISO/ IEC, 1991; Nielsen, 1993, 2000; Rosenbaum, 1989; Rubin, 1994; Shackel 1991). These properties were adapted to e-learning courseware usability (See Appendix).

- Use a different population sample: graduate students enrolled in an entirely on-line program as recommended by Koohang (2004); and

- In addition to examining e-learners' current views about the applied usability of their current e-learning courseware, also examines the perceived importance of e-learning usability design features held by e-learners.

\section{Purpose of the Study}

The purpose of the present study is to assess 1) users' current views about applied e-learning usability and 2) users' perceived importance of e-learning usability design features. Users' current views are important because they reveal what users believe about the usability of existing elearning courseware. Users' perceived importance of e-learning usability is important to study since it reveals what users believe e-learning courseware ideally should be in respect to usability.

Recent studies of undergraduates in the area of Web-based distance learning have shown that increased experience with the Internet and more time spent using the e-learning courseware are closely associated with higher users’ perceptions (Koohang, 2004; Koohang \& Durante, 2003; Koohang \& Weiss 2003). Therefore, the present study takes into consideration these two variables to determine whether similar results might be found using a graduate student sample.

Accordingly, this study will describe the characteristics of users' current views about applied elearning usability and users' perceived importance of e-learning usability design features are designed. In addition, the following research questions (RQ) will be answered:

RQ1: Does increased level of users' prior experience with the Internet influence their current views about applied e-learning usability?

RQ2: Does greater amount of time spent by users on the e-learning courseware influence their current views about applied e-learning usability?

RQ3: Does increased level of users' prior experience with the Internet influence their perceived importance of e-learning usability design features? 
RQ4: Does greater amount of time spent by users on the e-learning courseware influence their perceived importance of e-learning usability design features?

\section{Methodology}

\section{Instrument}

The instrument used in this study includes two measuring parts: 1) users' current views about applied e-learning courseware usability and 2) users' perceived importance of e-learning usability design features. (The Appendix shows the instrument.)

Users' current views about e-learning courseware usability part of the instrument was originally designed and validated by Koohang (2004). The present study adapted and refined this instrument by expanding the original 17-item scale to 19 items with the assistance from a panel of experts that consisted of four university professors who had extensive experience in the field of information science and information technology. The two additional items are feedback and direction. Since e-learning courseware are interactive and are used in an iterative manner, the provision of feedback and directions are key usability properties that need to be examined. The panel of experts concluded that all 19 items represent usability properties that are inherent to e-learning courseware.

A five-point Likert scale was used to assess each e-learning usability property for users' current views about applied e-learning courseware usability. The scale's descriptors were strongly agree $=5$, agree $=4$, neither agree nor disagree $=3$, disagree $=2$, and strongly disagree $=1$.

To examine users' perceived importance of e-learning usability, a similar scale was developed based on the 19 usability properties. For this portion of the instrument the scale's descriptors were: 5 = Very Important, 4 = Important, 3 = Somewhat Important, 2 = Slightly Important, 1 $=$ Not Important at all.

It must be noted that the two scales share parallel structure and utilize the same 19 usability properties inherent to the usability of e-learning courseware. The parallel nature of the scales allows evaluation of sets of user views in different cognitive structure. The users' current views about the usability of e-learning courseware scale is intended to tap current views held by e-learners in regard to applied e-learning courseware usability. The perceived importance of e-learning usability scale is intended to tap design ideals held by e-learners.

Forty three graduate students independent of the sample of respondents used in the study itself were used to further ensure the reliability of the instrument. The calculated coefficient alpha reliability from the results for users' current views about applied e-learning courseware usability and users' perceived importance of e-learning usability design features were .95 and .97 respectively. These results suggest that the instrument is stable enough and provide suitable consistency.

\section{Participants \& Procedure}

Data were collected electronically via the Internet from 101 graduate students enrolled in an interdisciplinary information science graduate e-learning program at a large state university in the Midwest, USA. The subjects were males and females with different ages from various states within the USA. At the time of data collection, the subjects were taking courses such as Microcomputer Information Resources Management, Information Marketing, Information Retrieval/Storage Systems, Knowledge Management, and XML programming. The program consists of 36 semester credits. It is completely on-line and uses a popular e-learning platform to deliver instruction via the Internet. The program uses the state-of-the-art technology to support the elearning instruction. For example, asynchronous audio and video streaming, presentation soft- 
ware, and live synchronous video lectures/office hours are used to support the delivery of elearning.

The subjects were advised that their participation in the study was voluntary. All participants were 18 years or older. The subjects were guaranteed anonymity with regard to the publication of the results.

\section{Data Analyses}

Descriptive analyses were conducted on collected data to describe the characteristics of users' current views about applied e-learning courseware usability and users' perceived importance of elearning usability design features. To answer the research question, collected data were analyzed by conducting six separate one-way analysis of variance (ANOVA) The one-way ANOVA technique produces a one-way analysis of variance for a quantitative dependent variable by a single factor -- independent variable. ANOVA tests the hypothesis that several means are equal. The predetermined level of significance (alpha $=.05$ ) was chosen.

\section{Results}

\section{Descriptive}

Table 1 includes the descriptive analysis for users' current views about the actual usability design of an e-learning courseware. It shows the mean score and standard deviation for each e-learning usability property. All items were above the mid-point of the five-point scale. The total mean score was 3.80.

Table 1: Descriptive for Users' Current Views

\begin{tabular}{|c|c|c|c|c|c|}
\hline E-Learning Usability Properties & $\mathbf{N}$ & Min & Max & Mean & SD \\
\hline Simplicity & 101 & 2 & 5 & 4.050 & 0.712 \\
\hline Comfort & 101 & 3 & 5 & 4.178 & 0.477 \\
\hline User-friendliness & 101 & 2 & 5 & 3.832 & 0.813 \\
\hline Control & 101 & 2 & 5 & 3.485 & 0.945 \\
\hline Navigability & 101 & 2 & 5 & 3.891 & 0.969 \\
\hline Load/access time & 101 & 1 & 5 & 3.574 & 1.003 \\
\hline Readability & 101 & 2 & 5 & 4.020 & $\overline{0.774}$ \\
\hline Adequacy/Task Match & 101 & 1 & 5 & 3.446 & 1.024 \\
\hline Link Visibility & 101 & 2 & 5 & 4.079 & 0.560 \\
\hline High \& readable color contrast & 101 & 2 & 5 & 4.000 & 0.812 \\
\hline Appropriate font type and size & 101 & 2 & 5 & 4.030 & 0.727 \\
\hline Well organized & 101 & 2 & 5 & 3.832 & 0.825 \\
\hline Visual Presentation & 101 & 2 & 5 & 3.733 & 0.882 \\
\hline Recognition & 101 & 2 & 5 & 3.851 & 0.753 \\
\hline Information relevancy & 101 & 2 & 5 & 3.970 & 0.685 \\
\hline Right to the point information & 101 & 2 & 5 & 3.644 & 0.923 \\
\hline Consistency & 101 & 2 & 5 & 3.842 & 0.914 \\
\hline Feedback & 101 & 1 & 5 & 3.356 & 1.045 \\
\hline Direction & 101 & 1 & 5 & 3.406 & 1.051 \\
\hline
\end{tabular}


Table 2 shows the descriptive analysis for users' perceived importance of e-learning usability. The mean score and standard deviation for each e-learning usability property indicate that all items are above 4.0. The total mean score was 4.37.

Table 2: Descriptive for Users' Perceived Importance

\begin{tabular}{|r|l|r|r|r|l|}
\hline E-Learning Usability Properties & $\mathbf{N}$ & Min & Max & Mean & SD \\
\hline Simplicity & 101 & 3 & 5 & 4.475 & 0.642 \\
\hline Comfort & 101 & 3 & 5 & 4.317 & 0.706 \\
\hline User-friendliness & 101 & 3 & 5 & 4.713 & 0.516 \\
\hline Control & 101 & 2 & 5 & 4.267 & 0.786 \\
\hline Navigability & 101 & 3 & 5 & 4.703 & 0.501 \\
\hline Load/access time & 101 & 3 & 5 & 4.545 & 0.625 \\
\hline Readability & 101 & 2 & 5 & 4.426 & 0.622 \\
\hline Adequacy/Task Match & 101 & 2 & 5 & 3.960 & 0.799 \\
\hline Link Visibility & 101 & 3 & 5 & 4.218 & 0.657 \\
\hline High \& readable color contrast & 101 & 2 & 5 & 4.069 & 0.803 \\
\hline Appropriate font type and size & 101 & 2 & 5 & 4.139 & 0.762 \\
\hline Well organized & 101 & 3 & 5 & 4.644 & 0.502 \\
\hline Visual Presentation & 101 & 2 & 5 & 4.069 & 0.738 \\
\hline Recognition & 101 & 3 & 5 & 4.376 & 0.598 \\
\hline Information relevancy & 101 & 3 & 5 & 4.564 & 0.518 \\
\hline Consistency & 101 & 2 & 5 & 4.238 & 0.750 \\
\hline Feedback & 101 & 3 & 5 & 4.436 & 0.623 \\
\hline Direction & 101 & 3 & 5 & 4.525 & 0.540 \\
\hline & & & & \\
\hline & & & & \\
\hline
\end{tabular}

Figure 1 shows a graphic representation of users' current views about the actual usability design of an e-learning courseware (first bar) and users' perceived importance of e-learning usability (second bar). The mean scores for all usability properties were higher for users' perceived importance of e-learning usability.

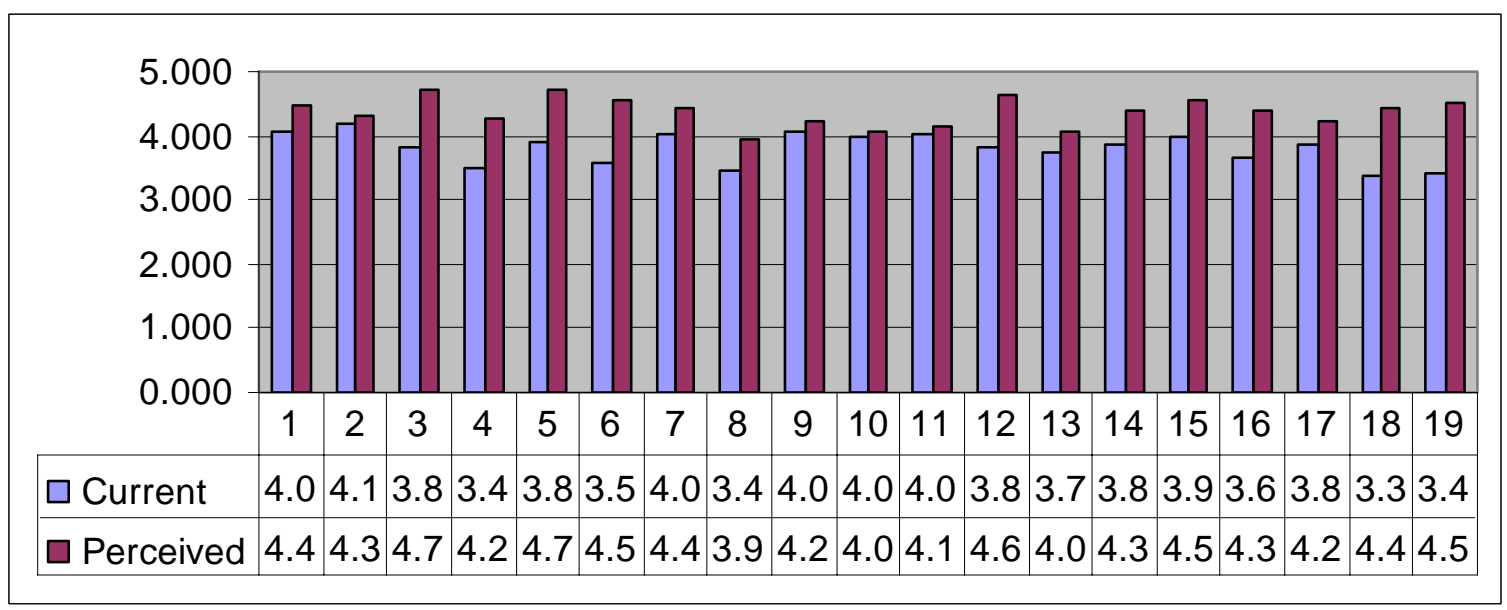

Figure 1: Users' current views and their perceived importance compared.

1 = Simplicity, 2 = Comfort, $3=$ User-friendliness, $4=$ Control, $5=$ Navigability, $6=$ Load/access time, $7=$ Readability, 8 = Adequacy/Task Match, $9=$ Link Visibility, $10=$ High \& readable color contrast, $11=$ Appropriate font type and size, 12 = Well organized, $13=$ Visual Presentation, $14=$ Recognition, $15=$ Information relevancy, $16=$ Right to the point information, $17=$ Consistency, $18=$ Feedback, $19=$ Direction 


\section{One-way ANOVAs}

RQ1: Does increased level of users' prior experience with the Internet influence their current views about applied e-learning usability? The results of ANOVA for users' prior experience with the Internet yielded a significant difference for users' current views about the e-learning usability $\left(F_{1,99}=12.176, p=.001\right)$. Increased level of users' prior experience influenced users' current views about the applied e-learning usability.

RQ2: Does greater amount of time spent by users on the e-learning courseware influence their current views about applied e-learning usability? The results of ANOVA for the amount of time spent on the e-learning courseware showed a significant difference for users' current views about the e-learning usability $\left(\mathrm{F}_{2,98}=15.092, p=.000\right)$. Greater amount of time users spent on the elearning courseware influenced users' current views about applied e-learning usability.

RQ3: Does increased level of users' prior experience with the Internet influence their perceived importance of e-learning usability design features? The results of ANOVA for users' prior experience with the Internet yielded a significant difference for users' perceived importance of elearning usability design features $\left(\mathrm{F}_{1,99}=.579, p=.449\right)$.

RQ4: Does greater amount of time spent by users on the e-learning courseware influence their perceived importance of e-learning usability design features? The results of ANOVA for the amount of time spent on the e-learning courseware showed a significant difference for users' perceived importance of e-learning usability design features $\left(\mathrm{F}_{2,98}=5.613, p=.005\right)$. Greater amount of time users spent on the e-learning courseware influenced users' perceived importance of e-learning usability design features

Means and standard deviations for prior experience with the Internet, and the amount of time users spent weekly on the e-learning courseware are shown in Tables 3 and 4.

Table 3: Users' Prior Experience with the Internet

\begin{tabular}{|r|r|r|r|c|}
\hline & & & & \\
\hline & & $\mathrm{N}$ & \multicolumn{1}{c|}{ Mean } & \multicolumn{1}{c|}{ SD } \\
\hline Users' Current Views & 3 - 5 Years & 22 & 3.486 & 0.350 \\
\hline & Over 5 Years & 79 & 3.886 & 0.505 \\
\hline & Total & 101 & 3.799 & 0.502 \\
\hline Users' Perceived Importance & 3 - 5 Years & 22 & 4.316 & 0.287 \\
\hline & Over 5 Years & 79 & 4.380 & 0.368 \\
\hline & Total & 101 & 4.366 & 0.352 \\
\hline
\end{tabular}

Table 4: Amount of time spent on the e-learning courseware

\begin{tabular}{|r|r|r|r|l|}
\hline & & \multicolumn{1}{|c|}{ N } & \multicolumn{1}{c|}{ Mean } & \multicolumn{1}{c|}{ SD } \\
\hline Users' Current Views & Less than hours & 18 & 3.383 & 0.251 \\
\hline & $4-6$ hours & 31 & 3.681 & 0.421 \\
\hline & More than 6 hours & 52 & 4.013 & 0.502 \\
\hline & Total & 101 & 3.799 & 0.502 \\
\hline Users' Perceived Importance & Less than 4 hours & 18 & 4.231 & 0.320 \\
\hline & 4 - 6 hours & 31 & 4.263 & 0.353 \\
\hline & More than 6 hours & 52 & 4.475 & 0.332 \\
\hline & Total & 101 & 4.366 & 0.352 \\
\hline
\end{tabular}




\section{Discussion}

The ability to compare and contrast usability properties set in two cognitive frames, users' current views of e-learning courseware usability and users' perceived importance of e-learning courseware usability is a power analytical tool. That is, experienced usability can be assessed and perceived usability importance can be assessed. Differences between the two usability bases then can be analyzed and addressed.

In the present study e-learners perceive that their overall actual e-learning user experience is adequate, as indicated by a combined mean of 3.80 for the e-learning usability properties. However, e-learners desire improved usability. This desire for improved usability is indicated by a combined mean of 4.37 for users' perceived importance of these same properties.

Since the two survey instruments employed in this study share parallel construction, direct comparison of all usability properties is possible. In the case of all usability properties e-learners' perceptions of their actual experience is below these same learners' desired levels of usability.

The ability to compare and contrast usability properties set in different cognitive frames becomes a powerful design tool. That is, users' experiential reports and perceptual ideals allow targeted improvements of particular usability properties to be made.

For e-learning instructional designers, this study suggests a clear means to guide e-learning usability improvements. First, the e-learning usability properties have been acknowledged. Attention to these usability properties may result in a product with higher effectiveness, learnability, flexibility, understandability, memorability, reliability, user positive attitude, user satisfaction, and product/system attractiveness. Second, gaps between users' current views of e-learning usability and users' perceived importance of these same properties serve to focus remedial improvement efforts.

One of the key points in this study is the importance of the user involvement in the design process. E-learning design must shift from a programmer-perspective to a learner-perspective. That is, programmers/instructional designers must incorporate e-learners' experiential and perceptual feedback to build better-designed e-learning courseware.

This study found that users' (in this case graduate students') prior experience with the Internet and time spent using e-learning courseware is associated with higher reported levels of e-learning courseware usability. Thus, it appears that facility with the Internet usage and the e-learning itself positively influence users' perceptions of their experiences with e-learning courseware.

While this alone is a powerful finding, it is consistent with prior research reports (Koohang, 2004) As in the current study, facility with the Internet usage and time spent using e-learning courseware were positively associated with reported levels of e-learning courseware usability. Consequently, the current study asserts that the concept of usability is multi-dimensional with experience being the new dimension. The experience dimension clearly can improve usability design.

User-related attributes such as users' prior experience with the Internet and time spent using elearning courseware have theoretical importance as well. Koohang and du Plessis (2004) constructed a three element e-learning Instructional Design Process Model. The model consists of instructional design as expressed by content, usability as expressed by system features, and learning as expressed by user attributes. While the e-learning instructional design process model specifies system features, user attributes are treated as a black box and are not specified. Therefore, based on the weight of consistent and repeated research findings, prior experience with the Internet and e-learning courseware experience are two key components describing the user and his or her readiness to learn, and should be included in the model. Finally, higher levels of e-learner fa- 
cility with the Internet and the courseware itself should result in better e-learning outcomes. According to theories of cognitive psychology (Howard, 1983), humans store procedures of automatic processing and controlled processing in long-term memory. These processes differ in their requirements of access to working memory (to use a computer analogy, a limited capacity central processor). Automatic processing of a skill does not require the use of working memory for execution and thus does not interfere with the controlled process of learning new information. Therefore, e-learners who already have a high degree of the Internet and e-learning facility can concentrate on the course's content and not on the arcane nature of the e-learning's design. More mental energy can be expended on learning the subject matter not the medium and vehicle of delivery.

\section{References}

Adkins, S. (2002). The 2002 U.S. market for e-learning simulation - Executive summary. Retrieved July 15, 2004, from http://www.brandonhall.com/public/execsums/execsum_simmarket.pdf

Broderick, C. (2001) What is instructional design? Retrieved July 15, 2004, from http://www.geocities.com/ok_bcurt/whatisID.htm

Crowther \& Keller. (2004). Improving the quality and effectiveness of computer-mediated instruction through usability evaluations. British Journal of Educational Technology, 35 (3), 289-304.

Dumas, J. \& Redish, J. (1993). A practical guide to usability testing. Norwood, NJ: Ablex.

Egbert, J. \& Thomas, M. (2001). The new frontier: A case study in applying instructional design for distance teacher education. Journal of Technology and Teacher Education, 9 (3), 391-405.

Gold, S. (2001). A constructivist approach to online training for online teachers. Journal of Asynchronous Learning Networks, 5 (1). Retrieved July 15, 2004, from http://www.aln.org/publications/jaln/v5n1/v5n1_gold.asp

Guillemette, R. A. (1989). Usability in computer documentation design: Conceptual and methodological considerations. IEEE Transactions on Professional Communication, 32, 217-228.

Holms, M. (2002). Web usability \& navigation. New York: McGraw-Hill.

Howard, D. (1983). Cognitive psychology: Memory, language, and thought. New York: MacMillan.

Huang, H (2002). Toward constructivism for adult learners in online learning environments. British Journal of Educational Technology, 33 (1), 27-37.

Huang, H. (2000). Instructional technologies facilitating online courses. Educational Technology, 40 (4), 41-46.

International Organization for Standardization (ISO) 9241-11 (1998). Ergonomic requirements for office work with visual display terminals (VDTs) - Part 11 guidance on usability. Geneva, Switzerland: ISO.

International Organization for Standardization /International Electrotechnical Commission (ISO/IEC) 9126 (1991). Software product evaluation - Quality characteristics and guidelines for their use. Geneva, Switzerland: ISO.

Koohang, A. (2004). A study of users' perceptions toward e-learning courseware usability. International Journal on E-Learning, 3 (2), 10-17.

Koohang, A. \& du Plessis, J. (2004). Architecting usability properties in the e-learning instructional design process. International Journal on E-Learning, 3 (3), 38-44.

Koohang, A. \& Durante, A. (2003). Learners' perceptions toward the web-based distance learning activities/assignments portion of an undergraduate hybrid instructional model. Journal of Information Technology Education, 2, 105-113. Available online at http://jite.org/documents/Vol2/v2p105-113-78.pdf

Koohang, A. \& Weiss, E. (2003). Effect of prior experience with the Internet on graduate students' perception toward courseware usability and web-based distance learning instruction: An exploratory study in a hybrid instruction environment. Issues in Information Systems, 4 (2), 535-542. 
Learnframe. (2001). Glossary of e-learning terms. Retrieved July 15, 2004, from http://www.learnframe.com/aboutelearning/glossary.asp

Mehlenbacher, B. (2000). Designing web-based training: Combining usability issues and learning theory. Tutorial for IPCC-SIGDOC 2000 International Conference. Cambridge, MA.

Moore, M., \& Kearsley, G. (1996). Distance education: A systems view. Belmont, CA: Wadsworth.

Nielsen, J. (1993). Usability engineering. San Diego, CA: Academic Press

Nielsen, J. (2000). Designing Web usability: The practice of simplicity. Indianapolis: New Riders.

Pimentel, J. (1999). Design of net-learning systems based on experiential learning. Journal of Asynchronous Learning Networks, 3 (2). Retrieved July 15, 2004, from http://www.aln.org/publications/jaln/v3n2/v3n2_pimentel.asp

Randall, B. (2001). Effective Web design and core communication issues: The missing components in Web-based distance education. Journal of Educational Multimedia and Hypermedia, 4, 357-67

Rosenbaum, S. (1989). Usability evaluations vs. usability testing: When and why? IEEE Transactions on Professional Communication, 32, 210-16.

Rubin, J. (1994). Handbook of usability testing. New York: John Wiley.

Shackel, B. (1991). Usability - context, framework, design and evaluation. In B. Shackel \& S. Richardson (Eds.), Human factors for informatics usability (pp. 21-38). Cambridge: Cambridge University Press.

Sherry, L., \& Morse, R. (1995). An assessment of training needs in the use of distance education for instruction. International Journal of Educational Telecommunications, 1 (1), 5-22.

Simonson, M., Smaldino, S., Albright, M. \& Zvacek, S. (2000). Teaching and learning at a distance: Foundation of distance education. New Jersey: Prentice-Hall.

\section{Appendix}

\section{E-Learning Courseware Usability Survey}

The purpose of this survey is to gather information about e-learners' perceptions toward e-learning courseware usability. Please take a few minutes to complete this survey based on your experience with the e-learning courseware you have been using for your distance education course(s).

Please do not leave any questions or statements blank.

Notes:

1) Your participation in completing this survey is absolutely voluntarily.

2) You must be 18 years or older to complete this survey.

3) All your responses are kept confidential. Do not put your name on this survey.

\section{SECTION 1}

Please answer the following questions by circling the appropriate number:

Gender:

(1) Male

(2) Female

Years of Experience with the Internet:

(1) $1-2$ Years

(2) $3-5$ Years

(3) Over 5 Years 
I spend an average of hours/week on the Web-based Platform:

(1) Less than 4 hour

(2) 4 - 6 hours

(3) More than 6 hours

\section{SECTION 2}

Using the scale below, please indicate your response to each of the statements regarding the usability of the e-learning courseware you use for e-learning course(s).

\section{SCALE:}

5 = Strongly Agree, 4 = Agree, 3 = Neither Agree nor Disagree, 2 = Disagree, $1=$ Strongly Disagree

1. Simplicity: The e-learning courseware is uncomplicated, simple, and straightforward.

2. Comfort: I feel comfortable using the e-learning courseware.

3. User-friendliness: The e-learning courseware is easy to use.

4. Control: I feel in control throughout the e-learning courseware.

$\begin{array}{lllll}5 & 4 & 3 & 2 & 1 \\ 5 & 4 & 3 & 2 & 1 \\ 5 & 4 & 3 & 2 & 1 \\ 5 & 4 & 3 & 2 & 1\end{array}$

5. Navigability: I can easily get to where I want to go throughout the e-learning courseware.

6. Load/access time: I don't have to wait a long time for the pages to load.

7. Readability: I have no problem understanding the language used to present information.

\section{$\begin{array}{lllll}5 & 4 & 3 & 2 & 1\end{array}$}

8. Adequacy/Task Match: The information presented is enough. It is no more/no less than what I need to know.

9. Link Visibility: The links throughout the e-learning courseware are visible.

10. High color contrast: The color contrast of the text is high.

\section{$\begin{array}{lllll}5 & 4 & 3 & 2 & 1\end{array}$}

$\begin{array}{lllll}5 & 4 & 3 & 2 & 1\end{array}$

$\begin{array}{lllll}5 & 4 & 3 & 2 & 1\end{array}$

11. Appropriate font type and size: The type and size of the fonts used to present information are appropriate.

$\begin{array}{lllll}5 & 4 & 3 & 2 & 1\end{array}$

12. Well- organized: The information in every page is well-organized and structured.

$\begin{array}{lllll}5 & 4 & 3 & 2 & 1\end{array}$

13. Visual Presentation: The visual presentation such as text boldfacing, italicizing, and underlining exist.

\section{$\begin{array}{lllll}5 & 4 & 3 & 2 & 1\end{array}$}

14. Recognition: I quickly recognize the key points presented throughout the e-learning courseware.

$\begin{array}{lllll}5 & 4 & 3 & 2 & 1\end{array}$

15. Information relevancy: The information presented is relevant to what I am supposed to learn.

16. Right to the point information: The information is concise and right to the point.

$\begin{array}{lllll}5 & 4 & 3 & 2 & 1\end{array}$

17. Consistency: There is consistency of appearance, terms, words, and action throughout the elearning courseware.

18. Feedback: The e-learning courseware provides feedback.

$\begin{array}{lllll}5 & 4 & 3 & 2 & 1 \\ 5 & 4 & 3 & 2 & 1\end{array}$

19. Direction: Directions on operating the e-learning courseware are given when I need them. 


\section{SECTION 3}

Using the scale below, please rate the importance of each of the usability properties to your use of the elearning courseware.

\section{SCALE:}

5 = Very Important, 4 = Important, 3 = Somewhat Important, 2 = Slightly Important, 1 = Not Important at all

1. The importance of Simplicity (Simple \& straightforward to use)

2. The importance of Comfort (Being at ease with the e-learning courseware)

3. The importance of User-friendliness (User-friendly, easy to use e-learning courseware)

$\begin{array}{lllll}5 & 4 & 3 & 2 & 1\end{array}$

4. The importance of Control (User being in control of e-learning courseware)

5. The importance of Navigability (Being able to easily move around throughout the e-learning courseware)

\section{$\begin{array}{lllll}5 & 4 & 3 & 2 & 1\end{array}$}

6. The importance of Load time (Not having to wait a long time for information to load)

$\begin{array}{rrrrr} & 5 & 3 & 2 & 1\end{array}$

7. The importance of Readability (understanding the language used to present information)

$\begin{array}{lllll}5 & 4 & 3 & 2 & 1\end{array}$

8. The importance of Adequacy/Task Match (enough information, no more, no less)

9. The importance of Link Visibility (visible links)

10. The importance of High color contrast (High color contrast for presenting information)

11. The importance of Font type and size (Appropriate font type and size)

12. The importance of Well-organized (Well-organized and structured)

13. The importance of Visual Presentation (Presence of text boldfacing, italicizing, and underlining)

14. The importance of Recognition (Being able to quickly recognize the key points)

15. The importance of Information relevancy (Relevant information)

16. The importance of Right to the point information (brief, short, and right to the point information)

$\begin{array}{lllll}5 & 4 & 3 & 2 & 1\end{array}$

17. The importance of Consistency (consistency of appearance, terms, words, actions)

18. The importance of Feedback (Providing feedback to users)

$\begin{array}{lllll}5 & 4 & 3 & 2 & 1\end{array}$

19. The importance of Direction (Providing direction to users) 


\section{Biography}

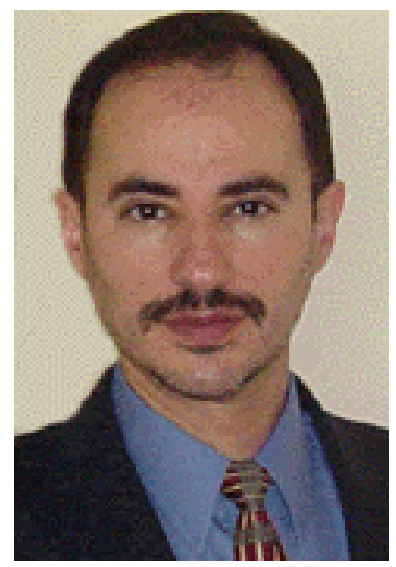

Dr. Alex Koohang is an associate professor and director of undergraduate program in the School ofInformation Studies at University of Wisconsin -Milwaukee, USA. Dr. Koohang's current research interests are in the areas of e-learning, learning object, usability, and information architecture. 